Alan S. Abrahams

is Assistant Professor of Business Information Technology at Virginia Tech, and an advisor to The Online Business Guidebook. He has taught at the Wharton business school and holds a $\mathrm{PhD}$ in Computer Science from Cambridge.

\section{Tarun Chaudhary}

is a 2009 MBA graduate from

Virginia Tech, and has over

2 years of project management consulting experience with USA and Indian organizations.

\section{Jason K. Deane}

is Assistant Professor of Business Information Technology at Virginia Tech. He received a $\mathrm{PhD}$ in Decision and Information Sciences from the University of Florida, and an MBA and BS in Business Administration from Virginia Tech.

Keywords: email marketing, spam, opt-in, franchise corporations

\section{Papers}

\section{A multi-industry, longitudinal analysis of the email marketing habits of the largest United States franchise chains}

\author{
Alan S. Abrahams, Tarun Chaudhary and \\ Jason K. Deane \\ Received: 2nd November 2009
}

\begin{abstract}
In this paper, we analyze the prevalence and frequency of email marketing among 200 of the largest franchise corporations in the United States, and compare the deliverability of emails in various industries - that is, how often legitimate, solicited emails were regarded by major hosted email providers as spam. We found that approximately half (45 per cent) of large franchise corporations provide opt-in email marketing newsletters, with email marketing being most popular in the hotel and health care industries and least popular in the pet and maintenance industries. Most corporations sent an average of one email every 10 weeks, predominantly on weekdays. Companies in the hotel and food industries were the most prolific email marketers, and hotels showed an unusual proclivity for emailing on Sundays. Surprisingly, an astonishing one-third of legitimate emails, on average, were flagged as spam by major email hosting providers. Food and automotive companies were most susceptible to deliverability issues, and hotel and personal care companies were relatively immune to deliverability problems. Our results provide an interesting comparison of the email marketing habits of large US franchise companies in a variety of industries, and suggest a variety of questions and action items for digital marketing professionals.

Journal of Direct, Data and Digital Marketing Practice (2010) 11, 187-197. doi:10.1057/dddmp.2009.31
\end{abstract}

\section{Introduction}

Email marketing is a cost-effective and powerful method of direct marketing. However, it can also be hugely challenging, as firms constantly teeter along the slippery slope of spam. Companies are 


\section{Opt-in email marketing}

\section{A cross-industry study of email marketing practices}

eager to develop email campaigns that deliver messages that consist of useful ideas and concepts for their reader base, and wrap in a minimal amount of well thought-out, targeted advertising for their products and services. If successful, this can be a mutually beneficial activity for both the company and the consumer. One of the most popular methods of achieving this goal is through 'opt-in' corporate newsletter services. In this study we take a closer look at this practice through a longitudinal empirical cross-industry analysis of opt-in email marketing by the top 200 companies from Entrepreneur magazine's Franchise 500 company ranking.

'Opt-in' newsletter services are growing in popularity, and are considered to be one of the safest methods of email marketing. ${ }^{1-3}$ In today's highly competitive global marketplace, firms need to maintain and build consumer trust and organizational reputation. Sending out mass unsolicited marketing materials via email has lost its lustre. Spam is bad. Needless to say, reputable organizations are not interested in being lumped into the spammer category; however, they also do not want to pass up the benefits of email marketing. To take advantage of this low-cost, high-return opportunity, many organizations are turning to 'opt-in' email service. These services allow consumers to add or remove their name from an email list at any point in time. Research has shown that this option elicits a much more positive response from consumers than unsolicited emailing. ${ }^{4}$ While on the list, consumers receive periodic emails containing a mix of useful retention information and marketing material. Executing this strategy successfully has obvious benefits, as audience members have a highly sought after quality: they are interested in the products as they have opted in to receive periodic information about them, and are hence more likely to make purchases.

However, reaching these consumers via email is often easier said than done. Internet Service Providers and other large email service providers such as Yahoo, Microsoft, AOL, Google, and Comcast bear a large cost of dealing with spam, and are therefore highly motivated to combat it. As a result they are constantly updating and improving their email spam filters. These spam filters represent a major threat to the successful execution of any email marketing campaign, as many well thought-out, well-intentioned emails often end up in the nondeliverable junk folder.

In an effort to learn more about the practices and experiences of a cross-industry sample of reputable organizations, we conducted a longitudinal field study of the 'opt-in' email marketing practices of the top 200 companies from Entrepreneur magazine's Franchise 500 listing of the largest US franchise corporations. We were eager to gain a better understanding of who the adopters of this 'opt-in' email marketing strategy were, how often and when they emailed consumers, and how frequently these emails were intercepted by popular email filters. Our goal was to highlight how different industries are approaching email marketing and how they are affected by antispam technologies. In doing so, we hope to provide some useful 


\section{Permission marketing has become more popular}

\section{... but anti-spam algorithms often block legitimate email campaign messages}

\section{Studying email marketing behaviours of America's largest franchise corporations}

information that might assist other organizations in benchmarking their email marketing tactics and performance against their industry peers.

\section{Related work}

Companies have long been attracted by the lure of advertising via email, ${ }^{5}$ with the tantalizing potential of near-zero communication costs leading to high return on campaign investments. Unfortunately, unsolicited commercial emails, or 'spam', have plagued consumers almost since the advent of email. ${ }^{6-15}$ The literature on techniques for combating spam is vast, with a variety of mechanisms proposed, including sophisticated computing techniques, ${ }^{16-27}$ informationeconomic approaches, ${ }^{28,29}$ and legislative approaches. ${ }^{4,7,30-32}$ While anti-spam computing techniques are often successful in combating spam, ${ }^{17,23}$ they regularly have the costly side effect of 'junking' legitimate email. ${ }^{33-35}$ In this paper, we look at the impact of anti-spam computing techniques on legitimate email marketing campaigns.

'Opt-in' email services ${ }^{36,37}$ - also known as email marketing ${ }^{38,39}$ or permission marketing ${ }^{1,3,40-43}$ services — have surged in popularity in recent years. With permission marketing, users 'opt in' to receive email updates from a company, allowing the company to send regular solicited emails to the customer. The popularity of email marketing is, in part, evidenced by the vast number of software products ${ }^{44}$ (both commercial and open source), and industry groups ${ }^{45}$ that assist firms with email marketing. This paper does not comment on the efficacy of any particular email marketing product or methodology.

Even the most complex anti-spam algorithms are not foolproof, and legitimate (solicited) marketing communications are often incorrectly routed to 'junk' folders. By some estimates, these false positives cost billions of dollars each year. ${ }^{34}$ Deliverability ${ }^{46}$ ensuring that a legitimate email gets past spam filters and into inboxes - has therefore become a major concern for corporate email marketers. A number of blacklisting technologies exist, ${ }^{47}$ and it can be a challenge for legitimate marketers to stay off the blacklists. This paper does not provide recommendations on improving deliverability or avoiding being blacklisted — we refer the reader to earlier work by other authors on this topic. ${ }^{46}$ Instead, we provide a substantive observation on the deliverability rates for major email marketing campaigns in various industries over an extended period of time.

While much literature exists on email marketing and spam, we are not aware of any cross-industry comparative studies on the prevalence and nature of email marketing among large corporations in America. In this paper, we attempt to address this gap in the literature by undertaking a multi-industry study of opt-in email marketing by America's largest franchise corporations. Our study differs from earlier work in that we do not comment on the effectiveness of permission marketing with customers, ${ }^{1,41,42}$ but rather observe email marketing 


\section{0 largest franchise corporations}

\section{Email campaigns over a 3 month period}

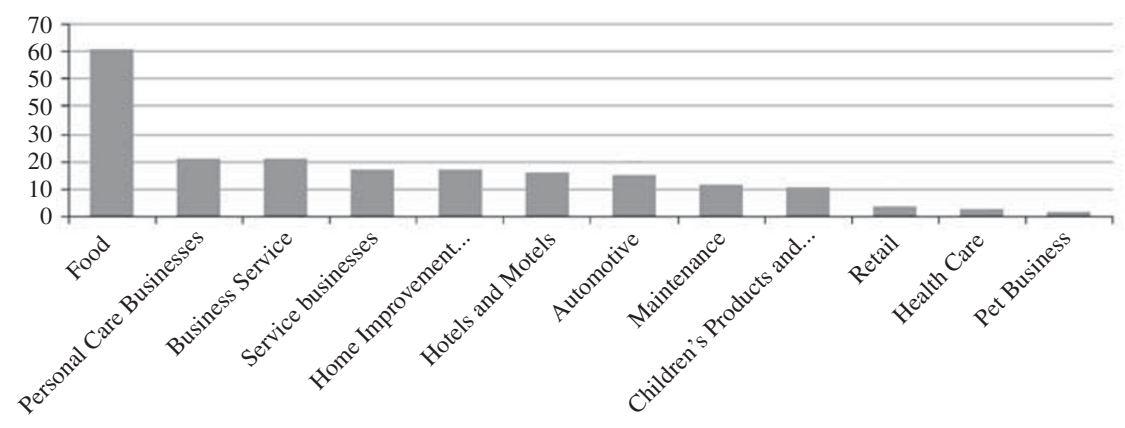

Figure 1: Industry distribution of top 200 franchise corporations in our study

behaviours in various industries (eg occurrence, timing, and frequency), and the magnitude of the false-positive spam problem across these industries.

\section{Methodology}

We began by gathering a list of the 200 largest franchise corporations in America, from the 2008 Franchise 500 listing published by Entrepreneur magazine. ${ }^{48}$ We chose to use large franchise corporations, as email marketing has compelling benefits to both franchisor and franchisee: the central franchise corporation is able to cheaply and professionally provide branded communications to customers and prospects of all franchisees. We categorized the companies in the Franchise 500 listing using the industry classification provided by Entrepreneur magazine. ${ }^{49}$ Figure 1 shows the quantitative makeup, by industry, of the top 200 companies. As is evident, over one-quarter of the companies in the top 200 largest franchise corporations were food-based businesses, with the remainder being predominantly personal care, business services, service businesses, home improvement, hotels, or automotive organizations.

Next, we established new email accounts with three of the most popular email service providers: Yahoo, Hotmail, and Gmail. We visited the websites of each of the 200 companies on our list and noted which companies did and did not provide 'opt-in' email newsletters. ${ }^{50}$ For those companies that were actively utilizing an 'opt-in' email service, we signed up for their service with all three email accounts. We monitored the inboxes and junk mail folders for each of our Yahoo, Hotmail, and Gmail email accounts on a daily basis, for a 14-week period from 12 May 2008 to 17 August 2008, to determine the frequency of emails and spam, from each company, and tabulated our results in a spreadsheet. Lastly, we aggregated all of the data in an effort to provide a useful summarization, a detailed analysis of which is provided in the next section.

\section{Results}

Of the 200 companies under analysis, only 89 companies (45 per cent) provided opt-in email newsletters. Figure 2 shows the percentage of 

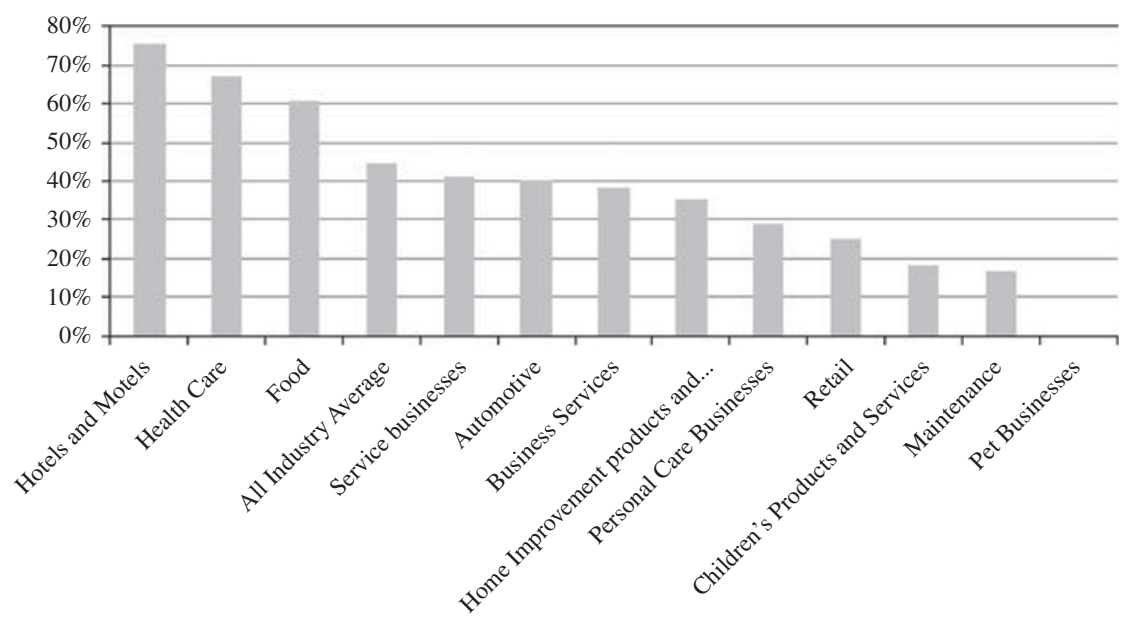

Figure 2: $\quad$ Percentage successful sign-ups for email newsletters, by industry

\section{Most companies still do not offer opt-in email newsletters}

\section{Email frequency varies greatly between industries}

companies in each industry that successfully allowed us to opt in for email newsletters. As is evident, the availability of email marketing newsletters as a proportion of total companies in the industry was highest in the hotel and motel, health care, and food industries. Surprisingly, companies in the children's products, maintenance, and pet industries were least likely to implement email marketing.

Figure 3 shows the average number of weeks between emails, for companies in each industry. On average, companies sent one email every 10 weeks (see bar labelled 'All Industries'). The hotels and food industries were the most frequent emailers, sending emails on average every 3 or 6 weeks, respectively. We noticed that some companies emailed with remarkable frequency: in the hotel industry, Hilton hotels accounted for the most emails, with an average of 4 per week, while in the food industry Domino's and Papa John's were most prolific, sending two to three emails per week. In contrast, business services, home improvement, and automotive companies sent emails on 


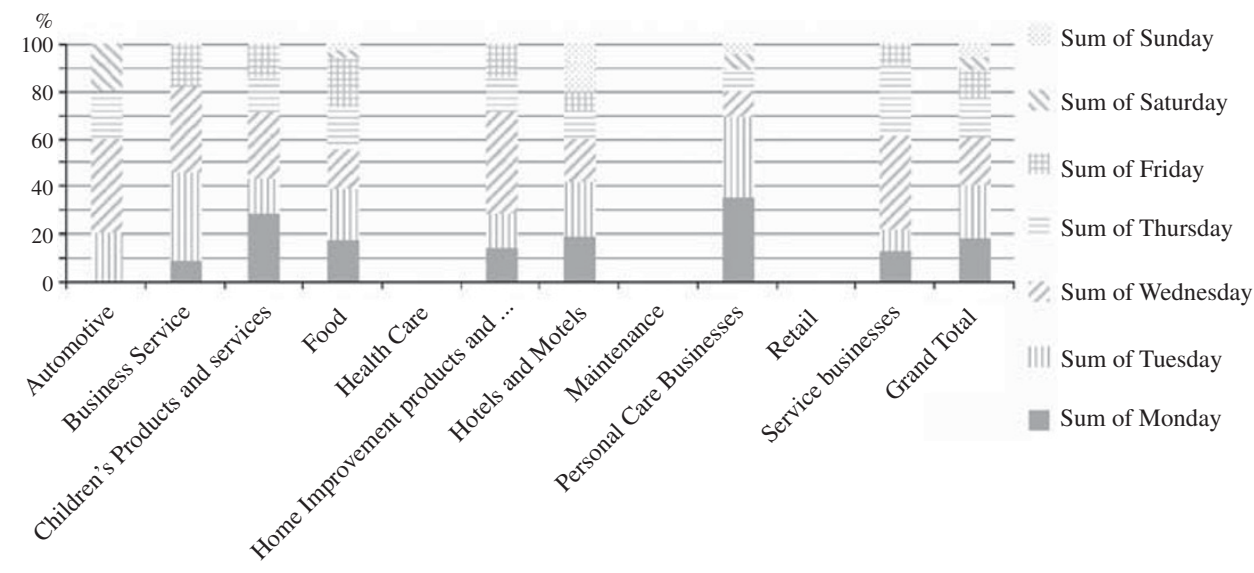

Figure 4: Most popular day of week to send emails, by industry

Table 1: Total emails routed to inbox and spam, for each email hosting provider

\begin{tabular}{lcccc} 
& \multirow{2}{*}{$\begin{array}{c}\text { Total emails } \\
\text { received }\end{array}$} & \multicolumn{2}{c}{ Emails routed to } & \multirow{2}{*}{$\%$ Spam } \\
\cline { 3 - 4 } & & Inbox & Spam & \\
\hline Google & 322 & 230 & 92 & 29 \\
Hotmail & 299 & 215 & 84 & 28 \\
Yahoo & 328 & 220 & 108 & 33 \\
\hline
\end{tabular}

\section{Popular weekdays for emails}

\section{One third of opt-in emails are trashed by spam filters}

average only once or twice per year. Companies in the health care, maintenance, and retail ${ }^{51}$ businesses did not send any emails during our study period.

Figure 4 shows the most popular day of the week to send emails, by industry - each column shows the number of emails sent on that weekday, for that industry. Most businesses chose to email only on weekdays, with Tuesdays and Wednesdays being the most popular days to email (see Grand Total column). The Hotel industry was unusual in that it often sent emails on Sundays. Interestingly, the personal care industry sent emails on Mondays and Tuesdays, presumably attempting to take advantage of the renewed vigour and self-improvement aspirations of consumers at the start of the week.

Surprisingly, we found that, across all email hosting providers, an average of approximately one in three opt-in emails were flagged as spam (see Table 1). A slightly different number of emails were received at each of our email accounts, though it is unclear whether this was caused by transmission problems by the sender or problems with the hosted email service itself. Yahoo was, by a small margin, the most aggressive filterer of spam emails.

Figure 5 shows the number of emails from companies in each industry that were regarded as spam. It would appear that the food, automotive, home improvement, and service industries are most vulnerable to having their emails flagged as spam, with 40 per cent or more of their emails being flagged. In contrast, companies in the 


\section{Studying more industries for a longer period}

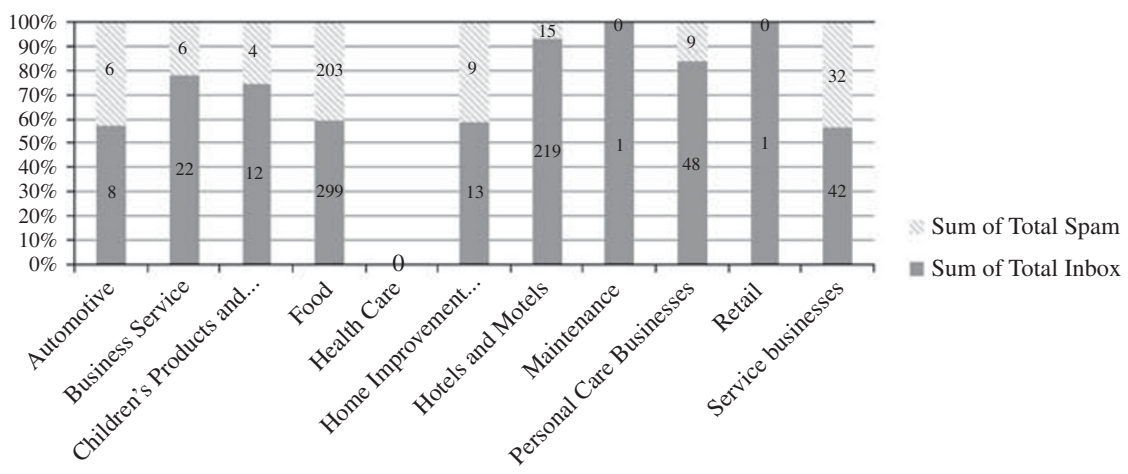

Figure 5: Number of emails regarded as spam, by industry

hotel and personal care industries were relatively immune to having their emails flagged as spam, with fewer than 20 per cent of their emails suffering from this issue.

\section{Limitations and future research}

The study reported in this paper has a number of limitations, including analysis period, breadth, and depth. The analysis period in our survey was only 14 weeks, as, due to the variety of email hosting providers, we needed to manually review and record each of the hundreds of emails received. Regarding breadth, we were limited to a survey of only 200 of the 500 companies in the Franchise 500, due to the sheer volume of emails that needed to be recorded. Although the Entrepreneur Magazine Franchise 500 has proved a popular data set for research, its limitations are well documented. ${ }^{52}$ Notably, the classification of companies into approximately a dozen major industries is limiting, and the data set is highly skewed towards food companies. A broader analysis of email marketing by both large and small corporations in more varied industries would be interesting. For example, it would be interesting, in the future, to study the largest non-franchising companies in the United States, and also to compare these to small companies, or to companies in other countries. Finally, it would be useful to conduct a deeper investigation into the reasons for non-deliverability of emails across varied industries, though such an investigation is difficult to undertake in a controlled fashion. Specifically, though, some anti-spam algorithms flag particular keywords or keyword combinations as spam, ${ }^{16}$ a variety of other non-deterministic anti-spam algorithms exist, especially collaborative filtering, ${ }^{22,25}$ and it may be hard to pinpoint different causes of non-deliverability across industries.

\section{Conclusions}

This paper provides an interesting longitudinal study of the email marketing habits of some of the largest franchise corporations in the United States, over a 14-week period. We analyzed the prevalence 


\section{Action items:}

\section{Offer opt-in emails}

\section{Set campaign frequency}

\section{Decide delivery day-of-week}

and frequency of email marketing among these companies, and investigated how often legitimate, solicited emails were regarded as spam by major hosted email providers. We found that approximately half ( 45 per cent) of large franchise corporations provide opt-in email marketing newsletters, with email marketing being most popular in the hotel and health care industries and least popular in the pet, maintenance, and children's products industries. Most corporations sent an average of one email every 10 weeks, usually on weekdays, with companies in the hotel and food industries being the most prolific email marketers. An astonishing one-third of emails on average were flagged as spam by major email hosting providers. Food and automotive companies were most susceptible to deliverability issues, and hotel and personal care companies were relatively immune to deliverability problems.

Our results provide some useful insights that can assist organizations in benchmarking their email marketing tactics and performance against their industry peers. In particular, our results suggest a number of pressing questions and checklist items for digital marketing professionals:

Question: Are competitors in your industry offering opt-in email marketing newsletters?

Action item: Consult the industry analysis in Figure 2. If email marketing is becoming pervasive in your industry, it may be time to start using hosted email marketing software, and deploy regular email marketing campaigns. You can find a sample of available email marketing software packages (including both paid commercial and free open-source options) under Related Work earlier in the paper. Question: Are your email marketing campaigns too frequent or too infrequent?

Action item: Compare your email frequency to other companies in your industry (see Figure 3). To ensure that you are not emailing customers too often, use the analytics features in your hosted email marketing software to check 'open' rates, 'click-through' rates, and campaign Return On Investment (ROI) for your emails. If the percentage of customers who open your emails is small, or few customers click on special offers inside your emails, or your campaign ROI is poor, your campaigns may be too frequent. In contrast, if your email marketing campaigns are infrequent whereas your competitors are contacting customers often, you might consider engaging more frequently with customers to strengthen brand awareness among your customers and build more regular repeat business.

Question: Are your email marketing campaigns scheduled on appropriate weekdays?

Action item: Compare your campaign schedule to other companies in your industry (see Figure 4). Again, low 'open' or 'click-through' rates, or poor campaign ROI, may indicate that your campaign scheduling needs adjustment - try a different weekday, when customers may be more active. 


\section{Use conventional direct mail where necessary}

Question: Are your email marketing campaigns ending up in consumer's spam boxes?

Action items: As evident in Figure 5, this problem is particularly troublesome in certain industries. Low 'open' or 'click-through' rates, or poor campaign ROI, may indicate that your emails are being flagged as spam. For suggestions on improving email deliverability, consult the study by Duffy ${ }^{46}$. For example, experiment with adjustments to your campaign contents. Conduct alpha and beta split tests, whereby alternative campaigns are sent to different segments of your email list. Replicate successful campaigns that perform well in these deliverability tests. In addition, many email marketing software packages are able to show you which customers never open your emails (eg due to your email arriving in the customer's spam box). Consider reaching these 'impossible to reach via email' customers via alternative means, such as traditional direct mail campaigns (eg postcards, hardcopy flyers, or full-color printed catalogues).

\section{References}

1. Godin, S. (1999) Permission Marketing: Turning Strangers into Friends, and Friends into Customers, Simon and Schuster, New York, NY, USA.

2. Krishnamurthy, S. (2001) 'A comprehensive analysis of permission marketing', Journal of Computer-Mediated Communication, Vol. 6, No. 2, Available at http://jcmc.indiana.edu/vol6/ issue $2 /$ krishnamurthy.html.

3. Rettie, R., Grandcolas, U. and Payne, V. (2002) 'Email marketing: Permission to PesterPaper presented to the Academy of Marketing Conference, Nottingham.

4. Sipior, J.C., Ward, B.T. and Bonner, P.G. (2004) 'Should spam be on the menu?', Communications of the ACM, Vol. 47, No. 6, pp. 59-63.

5. Martin, B.A.S., Durme , J.V., Raulas, M. and Mersavo, M. (2003) 'Email advertising: Exploratory insights from Finland', Journal of Advertising Research, Vol. 43, pp. 293-300.

6. Andrew, A.M. (2004) 'Internet newsletters and spam', Kybernetes, Vol. 33, No. 8, pp. 1244-1246.

7. Cerf, G. (2005) 'Spam, spim, and spit', Communications of the ACM, Vol. 48, No. 4, pp. 39-43.

8. Cranor, L.F. and LaMacchia, B.A. (1998) 'Spam!', Communications of the ACM, Vol. 41, No. 8, pp. 74-83.

9. Denning, P.J. (1982) 'Electronic junk', Communications of the ACM, Vol. 25, No. 3, pp. 163-165

10. Goodman, J., Cormack, G.V. and Heckerman, D. (2007) 'Spam and the ongoing battle for the inbox', Communications of the ACM, Vol. 50, No. 2, pp. 24-33.

11. Gopal, R.D., Walter, Z. and Tripathi, A.K. (2001) 'Admediation: New horizons in effective email advertising', Communications of the ACM, Vol. 44, No. 12, pp. 91-96.

12. Marchewka, J.T., Liu, C. and Petersen, C.G. (2003) 'Perceptions of unsolicited electronic mail or Spam', Journal of International Technology and Information Management, Vol. 12, No. 1, pp. 77-92.

13. Melville, N., Stevens, A., Plice, R.K. and Pavlov, O.V. (2006) 'Unsolicited commercial e-mail: Empirical analysis of a digital commons', International Journal of Electronic Commerce, Vol. 10, No. 4, pp. 143-170.

14. Pavlov, O., Melville, N. and Plice, R. (2005) 'Mitigating the tragedy of the digital commons: The problem of unsolicited commercial e-mail', Communications of the AIS, Vol. 16, pp. 73-90.

15. Schwartz, A. and Garfinkel, S. (1998) Stopping Spam: Stamping Out Unwanted Email and News Postings, Sebastopol, CA: O'Reilly Media. 


\section{桨. Abrahams, Chaudhary and Deane}

16. Androutsopoulos, I., Koutsias, J., Chandrinos, K.V. and Paliouras, G. (2000) 'An evaluation of naive Bayesian anti-spam filtering. Paper presented to the Workshop on Machine Learning in the New Information Age, 11th European Conference on Machine Learning, Barcelona, Spain.

17. Bratko, A., Filipi, B., Cormack, G.V., Lynam, T.R. and Zupan, B. (2006) 'Spam filtering using statistical data compression models', The Journal of Machine Learning Research, Vol. 7, (December), pp. 2673-2698.

18. Cournane, A. and Hunt, R. (2004) 'An analysis of the tools used for the generation and prevention of spam', Computers \& Security, Vol. 23, No. 2, pp. 154-166.

19. Duan, Z., Dong, Y. and Gopalan, K. (2007) 'DMTP: Controlling spam through message delivery differentiation', Computer Networks: The International Journal of Computer and Telecommunications Networking, Vol. 51, No. 10, pp. 2616-2630.

20. Fawcett, T. (2003) 'In vivo spam filtering: A challenge problem for data mining', $K D D$ Explorations, Vol. 5, No. 2, pp. 1-8.

21. Kim, H.J., Kim, H.N., Jung, J.J. and Jo, G.S. (2004) 'Spam mail filtering system using semantic enrichment in', Lecture Notes in Computer Science, Vol. 3306, Springer Berlin/ Heidelberg, pp. 619-628.

22. Kong, J.S., Rezaei, B.A., Sarshar, N., Roychowdhury, V.P. and Boykin, P.O. (2006) 'Collaborative spam filtering using e-mail networks', Computer, Vol. 39, No. 8, pp. 67-73.

23. Park, J.S. and Deshpande, A. (2006) 'Spam detection: Increasing accuracy with a hybrid solution', Information Systems Management, Vol. 23, No. 1, pp. 57-67.

24. Robinson, G. (2003) 'A statistical approach to the spam problem', Linux Journal, Vol. 107, (March), p. 3.

25. Shih, D.H., Chiang, H.S. and Lin, B. (2008) 'Collaborative spam filtering with heterogeneous agents', Expert Systems with Applications: An International Journal, Vol. 35, No. 4, pp. $1555-1566$.

26. Thorkildssen, H.W. (2004) 'SPAM — Different approaches to fighting unsolicited commercial email: A survey of spam and spam countermeasures', Network and System Administration Research Surveys, Vol. 1, pp. 45-55.

27. Wang, C.C. and Chen, S.Y. (2007) 'Using header session messages to anti-spamming', Computers \& Security, Vol. 26, No. 5, pp. 381-390.

28. Plice, R., Pavlov, O. and Melville, N. (2008) 'Spam and beyond: An information-economic analysis of unwanted commercial messages', Journal of Organizational Computing and Electronic Commerce, Vol. 18, No. 4, pp. 278-306.

29. Plice, R.K., Melville, N.P. and Pavlov, O.V. (2009) 'Toward an information-compatible antispam strategy', Communications of the ACM, Vol. 52, No. 5, pp. 128-130.

30. Nettleton, E. (2004) 'Electronic marketing and the new anti-spam regulations', Journal of Database Marketing \& Customer Strategy Management, Vol. 11, No. 3, pp. 235-240.

31. Ray, C. and Schmitt, J. (2003) 'Stopping spam: Federal and international initiatives', Journal of Internet Law, Vol. 7, No. 5, pp. 4-13.

32. Sorkin, D.E. (2001) 'Technical and legal approaches to unsolicited electronic mail', University of San Francisco Law Review, Vol. 35, No. 2, pp. 325-384.

33. Edwards, J. (2008) 'False positives equal lost business', IT Security, http://www.itsecurity .com/features/false-positives-022808/.

34. Gaudin, S. (2003) 'False positives: Spam's Casualty of war costing billions: Datamation', http://www.enterpriseitplanet.com/security/news/article.php/2246371.

35. Lueg, C. (2003) 'Spam and anti-spam measures: A look at potential impactsPaper presented to the Informing Science + Information Technology Education Joint Conference, Pori, Finland.

36. Gopal, R.D., Walter, Z. and Tripathi, A.K. (2006) 'Economics of first-contact email advertising', Decision Support Systems, Vol. 42, No. 3, pp. 1366-1382.

37. Resnick, R. (1997) 'The case for 'Opt In' marketing on the internet', Direct Marketing, Vol. 59, No. 12 , pp. $52-53$

38. Rizzi, J. (2001) 'Precision e-mail marketing', Direct Marketing, Vol. 64, No. 7, pp. 56-60. 


\section{Email marketing habits of the largest US franchise chains 浆}

39. Siwicki, B. (2008) 'Email marketing survey: Too much and not enough', Internet Retailer, Vol. 10, No. 10, pp. 39-42.

40. Kavassalis, P., Spyropoulou, N., Drossos, D., Mitrokostas, E., Gikas, G. and Hatzistamatiou, A. (2003) 'Mobile permission marketing: Framing the market inquiry', International Journal of Electronic Commerce, Vol. 8, No. 1, pp. 55-79.

41. Kent, R. and Brandal, H. (2003) 'Improving email response in a permission marketing context', International Journal of Market Research, Vol. 45 (December), pp. 489-503.

42. King, S. and Suntornpithug, N. (2008) 'Permission marketing: Email's off-line sales response', Proceedings of the American Society of Business and Behavioral Sciences, Vol. 15, No. 1, pp. 1257-1267.

43. Tizende, T., Smith, B. and Murphy, J. (2002) 'Getting permission: Exploring factors affecting permission marketing', Journal of Interactive Marketing, Vol. 16, No. 4, pp. 28-36.

44. Examples include: Sparklist.com, Campaigner.com, Lyris.com, Bronto.com, MailChimp.com, Mailworkz.com, ConstantContact.com, iContact.com, Topica.com, VerticalResponse.com, Arialsoftware.com, StrongMail.com, PHPList.com, YesMail.com, E-Dialog.com, Responsys .com, Epsilon.com, Experian Cheetahmail, Knowledge Marketing, BlueHornet.com, Zrinity .com, Whatcounts.com, ResponsiveEmail.com, ExactTarget.com, MyEmma.com, listrak.com, and dozens of others.

45. Examples include: ESPcoalition.org [Email Sender and Provider Coalition], EmailExperience .org [Email Experience Council], maawg.org [Messaging Anti-Abuse Working Group], and various blogs (eg Email-marketing-reports.com).

46. Duffy, S. (2007) 'New technology briefing: A guide to email deliverability for B2C email marketer', Journal of Direct, Data and Digital Marketing Practice, Vol. 9, No. 2, pp. 156-167.

47. For example: returnpath,net mxtoolbox.com/blacklists,aspx dmoz.org/Computers/Internet/ E-Mail/Spam/Blacklists, and others.

48. http://www.entrepreneur.com/franchises/rankings/franchise500-115608/2008,-1.html.

49. http://www.entrepreneur.com/franchises/retail/indexrt.html.

50. We considered only opt-in services where no purchase was necessary.

51. Under Entrepreneur magazine's industry classification, only one company in our study fell under the 'Retail' classification - Wireless Toyz, a retailer of cellular telephones, so the Retail industry under observation is not representative of the general retail industry.

52. Clarkin, J.E. and Hasbrouck, R.B. (2007) 'The Franchise $500^{\circledR}$ as a research tool: how objective and reliable is it?', Journal of Small Business and Enterprise Development, Vol. 14, No. 1, pp. 144-157. 